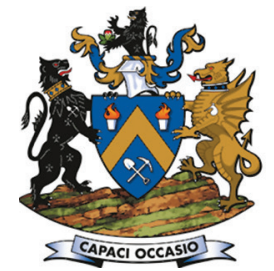

Affiliation:

${ }^{1}$ Missouri University of Science \& Technology, Rolla, MO, USA. 2University of Engineering and Technology Lahore, Pakistan.

Correspondence to:

M.U. Khan

Email:

usman@uet.edu.pk

Dates:

Received: 11 Mar. 2021

Revised: 25 Jul. 2021

Accepted: 26 Jul. 2021

Published: July 2021

How to cite:

Rehman, A. Ur, Emad, M.Z., and

Khan, M.U. 2021

Improving the environmental and economic aspects of blasting in surface mining by using stemming plugs.

Journal of the Southern African Insitute of Mining and Metallurgy, vol. 121, no. 7 , pp. 369-378

DOI ID:

http://dx.doi.org/10.17159/24119717/1573/2021

ORCID:

A. Ur Rehman

https://orcid.org/0000-0003-

2299-6251

M.Z. Emad

https://orcid.org/0000-00018537-8026

M.U. Khan

https://orcid.org/0000-00026260-6679

\section{Improving the environmental and economic aspects of blasting in surface mining by using stemming plugs}

\author{
A. Ur Rehman', M.Z. Emad' ${ }^{2}$, and M.U. Khan ${ }^{2}$
}

\section{Synopsis}

The use of stemming plugs in surface blasting is gaining popularity because of the environmental, technical, and economic advantages. Although previous studies have established the operational effectiveness of different types of stemming plugs, evaluations of the economic and ergonomic impacts are lacking, thereby hindering their application in many mining operations. Consequently, a significant proportion of mining operations end up performing less efficient blasts. We evaluated the effectiveness of three types of stemming plugs by conducting multiple full-scale production blasts. The results show that stemming plugs reduce the need for secondary blasting and increase blast performance. An economic analysis showed that the incorporation of stemming plugs can reduce blasting costs significantly.

\section{Keywords}

stemming plugs, economic analysis, blast performance, surface mining, confinement.

\section{Background}

Optimum utilization of explosive energy is a prime consideration in blasting due to rising costs, production pressures, financial challenges, environmental constraints, and other factors. Blast performance is usually measured in terms of rock fragmentation, the shape of the muckpile, and resulting blasting fumes. The explosive output affects the entire mining operation from post-blast scaling to the overall efficiency of the ore processing plant. Thus, minimization of the blasting cost, safety risks, and environmental impacts is extremely desirable in surface mining operations. All of these factors can be positively impacted by improved rock fragmentation (Mohamad et al., 2013; ur Rehman, 2017; ur Rehman, Emad, and Khan, 2019).

Increased mineral production demands have put immense pressure on mines and quarries. Surface mines use drilling and blasting as this is historically the most economical way of rock breakage. Existing operations primarily scale up production by increasing the blast size. This situation creates an imbalance between rock fragmentation and other blasting factors like ground vibration, flyrock, air blast, and post-blast fumes. Various blasting parameters affect blast efficiency and the optimization of optimizing these parameters to achieve an efficient blast is a complex process (Khandelwal and Singh, 2006; Singh and Singh, 2005; Yang and Liu, 2010; Yang et al., 2010). Zhu et al. (2008) state that blast performance depends on the blast geometry, rock mass properties, and explosive specifications. Mohamad et al. (2013) established that blast-hole diameter, stemming length, burden priming, spacing, and delays are important for blasting dynamics and hence the rock fragmentation.

On surface mines, the tops of the blast-holes are filled with an inert material, called stemming, after the hole has been charged,. This practice helps in confining explosives gases, improves rock fragmentation, and reduces flyrock. The stemming provides confinement for the gases created by detonation of the explosive. This helps improve rock fragmentation, prevents ejection of the collar rock, and increases safety. Stemming material redirects the explosives energy back into the rock to facilitate its breakage ( Cevizci, 2012). 


\section{Improving the environmental and economic aspects of blasting in surface mining}

Drill cuttings are most commonly used as a stemming material due to their availability at the hole collar (Halim Cevizci, and Ozkahraman, 2012). Thus, the stemming material for the blast-hole is mainly comprised of loose soil, dirt, and rock cuttings. An inherent problem with using drill cuttings as a stemming material is non-uniformity in terms of particle size and compaction. This sometimes leads to blowouts from the stemming section. Due to poor stemming practice, gas venting through the stemming material occurs and causes significant loss of explosive energy. Poor explosives energy distribution results in a less efficient blast in terms of rock fragmentation and increases the requirement for secondary blasting. The sudden liberation of gases due to poor stemming can also cause flyrock. Flyrock is a major safety hazard as it can injure personnel, and damage structures and equipment. Another prime blasting consideration, in addition to the type of stemming material, is the length (depth) of stemming material. A decrease in stemming length will increase the quantity of the explosive in a blast-hole, hence increasing the explosives cost, the charge per delay, and environmental and safety hazards. A transition from drill chipping towards aggregate as stemming material has been observed, as more and more mines are using aggregate as stemming material with excellent (Gomes-Sebastiao, G.L. and de Graaf, W.W. 2017).

The significance of stemming in blasting is an established topic that has been studied by various researchers (Cevizci, 2012, 2013, 2014; Cevizci and Ozkahraman, 2012; Choudhary and Rai, 2013a; Eloranta, 1994; Kojovic, 2005; Kopp, 1987; Mohamad et al., 2012; Rai and Imperial, 2005; Sazid, Saharan, and Singh, 2016; Sharma and Rai, 2015; Singh and Sastry, 1988; Trivedi, Singh, and Raina, 2014). The incorporation of stemming plugs as opposed to the conventional stemming material is gaining popularity in surface blasting operations. Stemming plugs are a well-known accessory used in blasting along with conventional stemming material. Various surface mines have been incorporating stemming plugs for the last three decades and numerous varieties of commercial plugs are currently available from several manufacturers. Different researchers have studied the efficacy of stemming plug compared to conventional stemming ( Cevizci, 2012; Choudhary and Rai, 2013a; Kojovic, 2005; Kopp, 1987; Mohamad et al., 2012; Rai and Imperial, 2005; Rai, Ranjan, and Choudhary, 2008; Sharma and Rai, 2015; Singh and Sastry, 1988). Various types of plugs, including air plugs, stemming plugs, small inflatable balloons, plaster of Paris packings, cement concrete, and grouting are used as stemming material.

Various researchers have compared the effects of stemming plugs and conventional stemming systems on rock fragmentation, and the shape of the muckpile. Laboratory experiments to test the effectiveness of stemming on rock fragmentation showed a $25 \%$ loss of energy when blast-holes were not stemmed (Zhang et al., 2020). Brinkmann (1990) established that inadequate stemming results in improper explosives confinement, causing about $50 \%$ loss in explosive energy due to premature venting through the collar of the blast-hole. Bartley (2002) reported that the incorporation of stemming plugs can increase gas retention for almost 50 milliseconds as compared to conventional stemming Eloranta ( 1994) used coarser stemming material with poured precast concrete, with a resulting reduction in the stemming ejection velocity. Brinkmann (1990) showed that the length of stemming plays an important role in blast design in the context of blowouts, as stemming blowouts result in excessive vibration and loss of confinement. He further concluded that a shorter stemming length and greater fines content are the most common reasons for stemming blowouts. The length of stemming was deemed critical by Chiapetta and Wyciskalla (2004), as a shorter length can result in blowouts and other collar-related problems. Jenkins and Floyd (2000) found that inadequate stemming results in more blowouts and boulders. Kojovic (2005) achieved an increased mill throughput and reduction in powder factor using fine aggregate stemming. Sazid, Saharan, and Singh (2012) concluded that stemming plugs control flyrock, improve fragmentation, achieve higher gas retention, eliminate boulder formation, and result in better utilization of explosive energy.

Different stemming plugs apart from conventional drill cuttings are used in the industry. Yang et al., (2018) reported that the use of stemming plugs increased gas retention and reduced explosive consumption. Cevizci and Ozkahraman (2012) reported that plaster of Paris stemming plugs improved fragmentation. Numerical simulation for stemming analysis showed an increase in gas pressure with plaster stemming ( Cevizci, 2019). Ramulu (2012) reported an improvement in tunnel advance by incorporating stemming plugs. Choudhary and Rai (2013b) found that poor fragmentation, an irregular final wall, oversized boulders, high dozing cost, and loose muckpile were improved by using stemming plugs. Sharma and Rai (2015) reported that stemming plugs improved fragmentation, machine utilization, and muckpile throw. A study in Portugal (Neves et al., 2016) found improved blast performance with the application of stemming plugs. Stemming plug application resulted in better machinery utilization and fewer loads lost (Gomes-Sebastiao and de Graaf, 2017). In another application of stemming plugs, it was found that funnel-shaped stemming plugs controlled flyrock and increased the velocity of detonation (Bhaskar et al., 2019). Recent research has suggested further evaluation of stemming plugs based on human factors and economics (ur Rehman, Emad, and Khan, 2020).

Even though stemming plugs have been utilized for almost three decades, their application is still new to many operations. The issue of technology adoption and consumer response is not limited to the mining industry, but has been observed and studied for different industries (Stavrakas, Papadelis, and Flamos, 2019).

The literature review comprehensively establishes the effectiveness of stemming plugs in different settings and concludes that stemming plugs are effective in improving blast performance. The engineering aspects of using stemming plugs are widely reported (Ipmawati et al., Nainggolan, Wiyono, and Sunarya, 2018; Kabwe, 2018; Kabwe and Banda, 2018; Marinho et al., 2017; Saharan, Sazid, and Singh, 2017). An assessment of the impact of blast-hole design parameters on the total cost of opencast operations showed the significant importance of economic analysis (Bilim, Çelik, and Kekeç, 2020). However, no study has evaluated the economic impact of incorporating stemming plugs in blasting. The current work constitutes a novel contribution to the literature as it evaluates the economic impact of using stemming plugs at a full-scale quarry blasting operation. We evaluated the application of stemming at a large full-scale surface quarry in Punjab, Pakistan and carried out a critical economic analysis and estimate of the cost effects. The study also discusses the acceptability of various stemming plugs among workers.

\section{Research methodology}

The project was carried out at the DG Khan Cement Company 


\section{Improving the environmental and economic aspects of blasting in surface mining}

Limited quarry located in District Chakwal, Pakistan. The quarry is located at $32^{\circ} 42^{\prime} 53.9^{\prime \prime} \mathrm{N} 72^{\circ} 49^{\prime} 32.3^{\prime \prime} \mathrm{E}$ (Google Earth, accessed 18 August 2015). The highest point at the quarry is $846 \mathrm{~m}$ above sea level with the lowest bench being developed at $777 \mathrm{~m}$ above sea level. The average limestone production from the quarry is about $16000 \mathrm{t} /$ day, and the plant production about $6700 \mathrm{t}$ of cement per day. The blasting engineer designs the blast pattern which is followed by the drillers. The holes are charged using an interval charging technique and filled with stemming material. The blasting connections are made according to the design and the blast is initiated. Successful blasts yield fragmentation within the crusher's size range, with flyrock and blast-induced vibrations under the permissible limits. Bench heights range from 11 to $14 \mathrm{~m}$ based on the strata and geology of the deposit. Figure 1 shows the plan view of the quarry.

Two rows of holes are drilled in a staggered blast pattern. Experiments were conducted by adding stemming plugs to the existing blasting system. No other amendment to the blast design was made. The angle of the drill-holes was kept at 15 degrees relative to the vertical face. The blast-hole burden was $4 \mathrm{~m}$ and the spacing $5 \mathrm{~m}$. Blast-hole depth was equal to bench height and sub-drill was $1 \mathrm{~m}$ for toe removal and smoother floor conditions. As per the blast design, $3 \mathrm{~m}$ of stemming was added in the top of the hole loaded with explosives. A combination of high explosives and blasting agent was used in each hole. The primer was dynamite (local name Wabox). After loading the primer the bottom charge was filled with boosters (local name Boosters) followed by ANFO blasting agent prepared at the site. All calculations were carried out following existing practice. When comparing different stemming devices with conventional stemming, all other blast design configurations were kept constant.

\section{Field evaluation}

The first type of stemming plug is the plastic moulded plug, as shown in Figure 2a and referred to as stemming plug 1. The application of stemming plug 1 required it to be inserted in the blast-hole after the explosives were loaded (Figure 2b). Once the plug had been inserted the rest of the hole was filled with conventional stemming material.

The second type of stemming plug comprised inflatable rubber balls, which are representative of air plugs as discussed in the literature. The air plug is referred to as stemming plug 2. Conventional stemming material of $0.5 \mathrm{~m}$ length was added before stemming plug 2 was inserted in the blast-hole. The upper

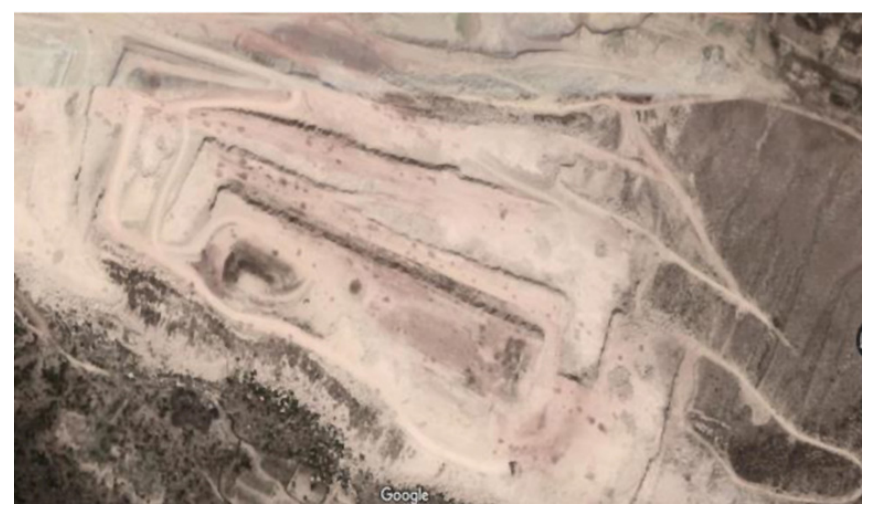

Figure 1-Plan view of DG Khan cement quarry (Google Maps, accessed 18 August 2015)

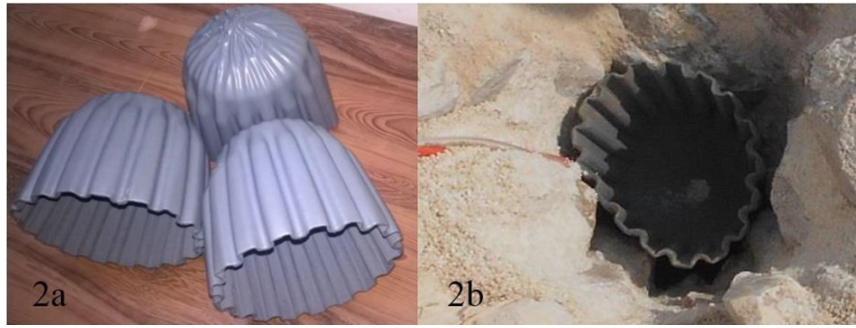

Figure 2-Stemming plug 1. (a) Plastic mould, (b) installation in blast-hole
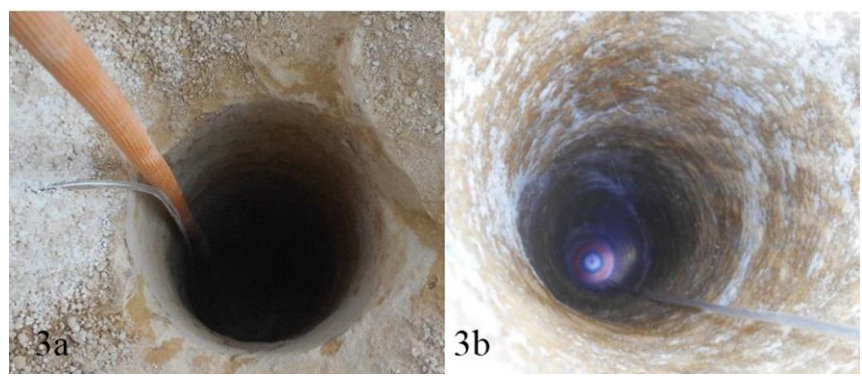

Figure 3-Stemming plug 2. (a) borehole with air line; (b) inflated plug

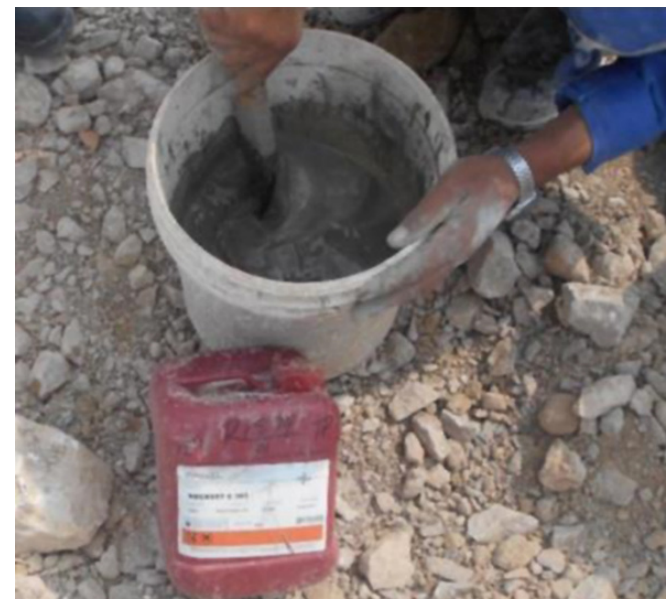

Figure 4-Stemming plug 3 (mortar preparation)

portion of the blast-hole was again filled with conventional stemming. Figure 3a shows stemming plug 2 being inserted, with an air line for inflating the ball, and Figure $3 \mathrm{~b}$ shows its final shape after installation in the blast-hole.

For the third type of stemming plug, cement mortar was used (stemming plug 3). Similar to the installation of stemming plug 2, $0.5 \mathrm{~m}$ of conventional stemming was first added, followed by stemming plug 3 in the form of a slurry (Figure 4). The rest of the blast-hole was filled with conventional stemming material.

The purpose of adding $0.5 \mathrm{~m}$ of conventional stemming before inserting stemming plug 2 was to avoid the formation of an air deck at top of the charged hole, whereas for stemming plug $30.5 \mathrm{~m}$ of conventional stemming was added to avoid contact of the mortar with the explosives. Both of these situations could have altered the explosive performance. Holes for conventional and experimental stemming plugs were initiated with a single initiator to avoid changes in rock mass conditions such as crack initiation, back-break, or anything emanating due to the adjacent blasting. 


\section{Improving the environmental and economic aspects of blasting in surface mining}

The fragmentation of the muckpile obtained after blasting was assessed by image analysis using Split Desktop software. This software processes images based on visible fragmentation. The most critical consideration was capturing the images of the muckpile. It was suggested that at least three images should be obtained with a high-resolution camera from different angles for a single analysis. The software allows the user to delineate the boundaries of the pile and particle sizes in the image for better processing. Sampling was carried out based on the directions accompanying the software. Three reference scales were placed at different distance for the best delineation. The images were then processed to determine the particle size distribution and ascertain the percentage of blast fragmentation. This work used three images per blast immediately after each blast; however, for better clarity and representation of the fragmentation size multiple images should be taken at regular intervals during muckpile loading. In this way, a comprehensive three-dimensional fragmentation result can be obtained. Future work should follow the suggested technique. A blast was categorized as a poor blast if it resulted in oversized boulders that required secondary blasting. Figure 5 shows the conventional stemming material.

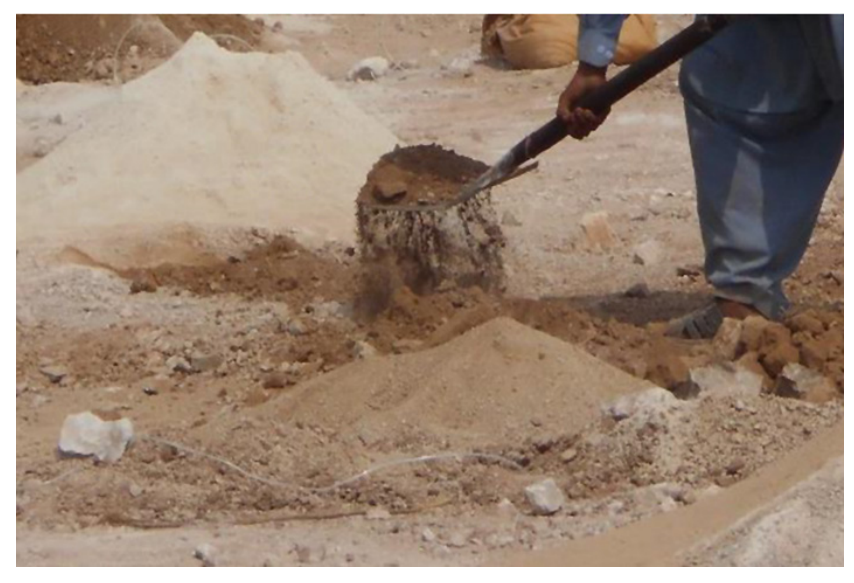

Figure 5-Conventional stemming material

\section{Table I}

\section{Summary of worker feedback regarding stemming plug} installation

\begin{tabular}{|l|c|c|c|}
\hline Aspect & Plug 1 & Plug 2 & Plug 3 \\
\hline Extra time required (minutes) & 1 & 7 & 5 \\
Adaptability & Low & Moderate & High \\
Failures in application & 0 & 30 & 0 \\
Recovery time/failure & 0 & 8 & 0 \\
No. of accessories & 0 & 1 & 3 \\
Worker evaluation & Positive & Neutral & Negative \\
\hline
\end{tabular}

A total of six full-scale production blasts were performed. The ground was marked with spray paint to differentiate between two types of blasts while capturing images for fragmentation analysis. The reference mark was corrected using GPS. A muckpile image can be seen in Figure 6a. A standard football of 9-inch diameter was used as a reference. The fines cut was kept at 6.5 to 12 inches based on the type of geological formation. The fines cut was higher for loose strata as during loading and maneuvering it was expected to be reduced to 6 inches, the crusher passing size. The blasting crew was not familiar with the usage of stemming plugs, so on-site training and demonstrations were done. Worker feedback was also collected for seven different aspects to gauge human factors related to the stemming plugs application. A summary of the feedback is given in Table I. The feedback was gathered based on the relative perceptions of workers for each stemming plug.

\section{Results and discussion}

Six full-scale blasts were performed - blasts 1,3 , and 5 with stemming plugs (types 1,2 , and 3 respectively), blasts 2 , 4, and 6 using conventional stemming material. The results for all six blasts are summarized in Table II. The results were evaluated based on the percentage of material below the fines cut, the percentage above the passing size of the crusher, and the top size after the blast.

Blasts 1 and 2 were performed at the same bench. Stemming plug 1 (plastic mould) was used in blast 1 , and conventional stemming in blast 2 . Blast 1 resulted in a $D_{50}$ of 12 inches and $D_{80}$ of 22 inches. The percentage of material below the fines cut was $27 \%$, with no material greater than the crusher's permissible limit. The largest boulder was 43.5 inches. Figure 6 shows the post-blast image and screenshot of the Split Desktop analysis.

For blast-2 the $D_{50}$ and $D_{80}$ were 2 and 10 inches, with $69 \%$ below the fines cut. The percentage of the material above the acceptable crusher limit was $5.25 \%$, and boulders requiring secondary blasting were also observed with a peak size of 143 inches. Figure 7 shows the post-blast image and screenshot from Split Desktop.

The fragmentation results of blast 3 were compared with those of blast 4 . Both these blasts were conducted at the same bench, with stemming plug 2 (inflated plug) employed in blast 3 and conventional stemming in blast 4 . The $D_{50}$ and $D_{80}$ for blast 3 were 11.5 and 40 inches respectively, with $15 \%$ of the material below the fines cut. No material above the crusher's input limit was observed, with the largest size being 63.41 inches. Figure 8 shows the post-blast image and Split Desktop screenshot. Blast 4 resulted in a $D_{50}$ of 20 inches and $D_{80}$ of 50 inches. The percentage of material below the fines cut was $20 \%$, with $8 \%$ larger than the size of the crusher's intake. The maximum particle size observed was 101 inches. Figure 9 shows the post-blast image and Split Desktop screenshot.

\section{Table II}

\section{Summary of blast results from Split Desktop}

\begin{tabular}{|l|c|c|c|c|c|c|c|}
\hline Blast no. & Stemming & $\boldsymbol{D}_{50}$ (inches) & $\boldsymbol{D}_{\mathbf{8 0}}$ (inches) & Fines cut size (inches) & Percentage below fines cut & Percentage above passing size & Maximum size (inches) \\
\hline 1 & Plug 1 & 12 & 22 & 9 & $27 \%$ & $0 \%$ \\
2 & No plug & 2 & 10 & 9 & $69 \%$ & $24.25 \%$ \\
3 & Plug 2 & 11.5 & 40 & 12 & $15 \%$ & $0 \%$ \\
4 & No plug & 20 & 50 & 12 & $20 \%$ & $8.03 \%$ \\
5 & Plug 3 & 15 & 35 & 6.5 & $28 \%$ & $0 \%$ \\
6 & No plug & 25 & 75 & 6.5 & $22 \%$ & 101.2 & $10.40 \%$ \\
\end{tabular}


Improving the environmental and economic aspects of blasting in surface mining
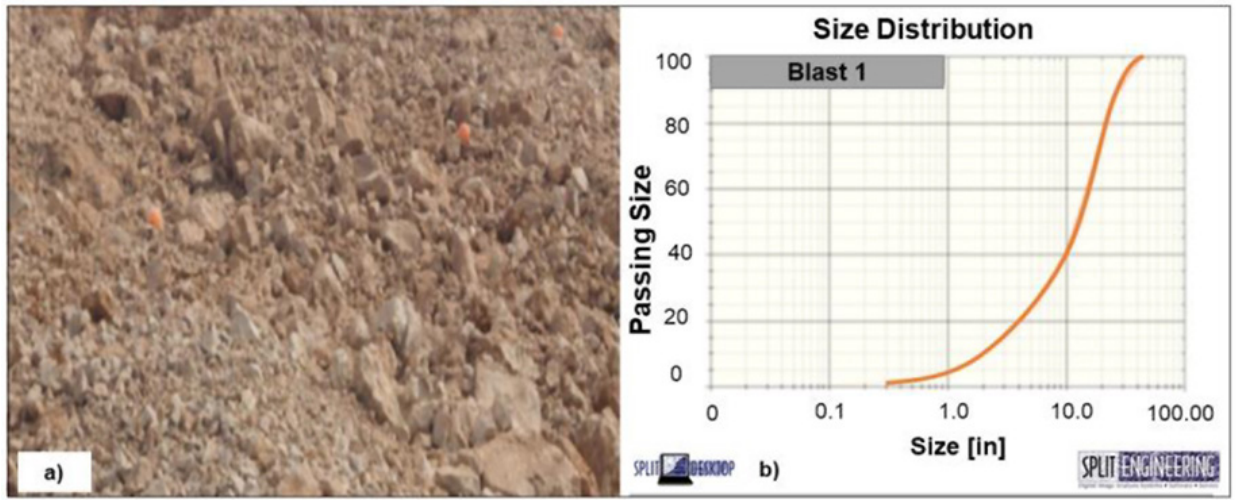

Figure 6-Blast 1. (a) Muckpile after the blast and (b) cumulative size distribution
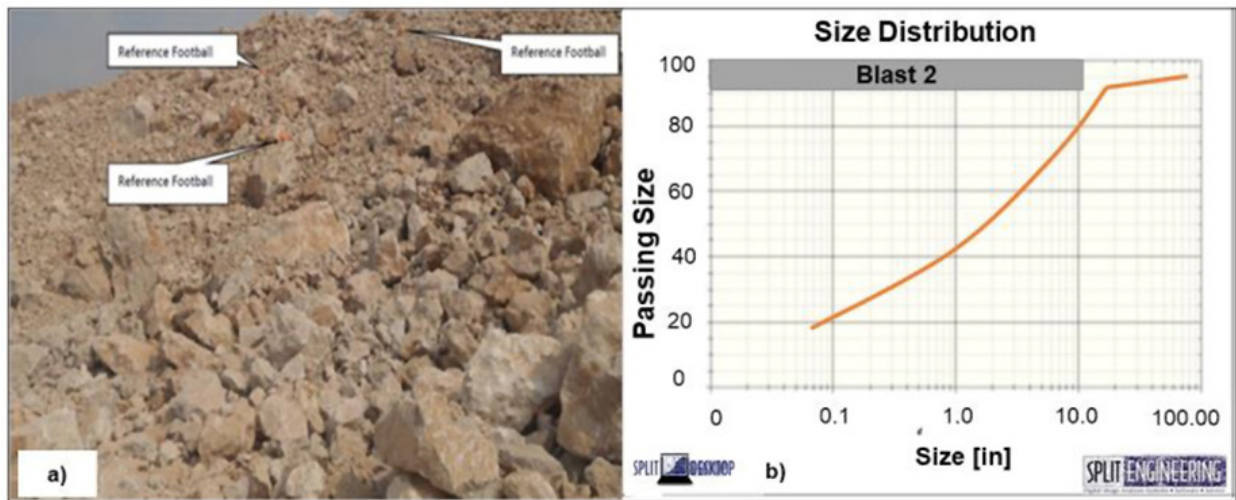

Figure 7-Blast-2. (a) Muckpile after the blast and (b) cumulative size distribution
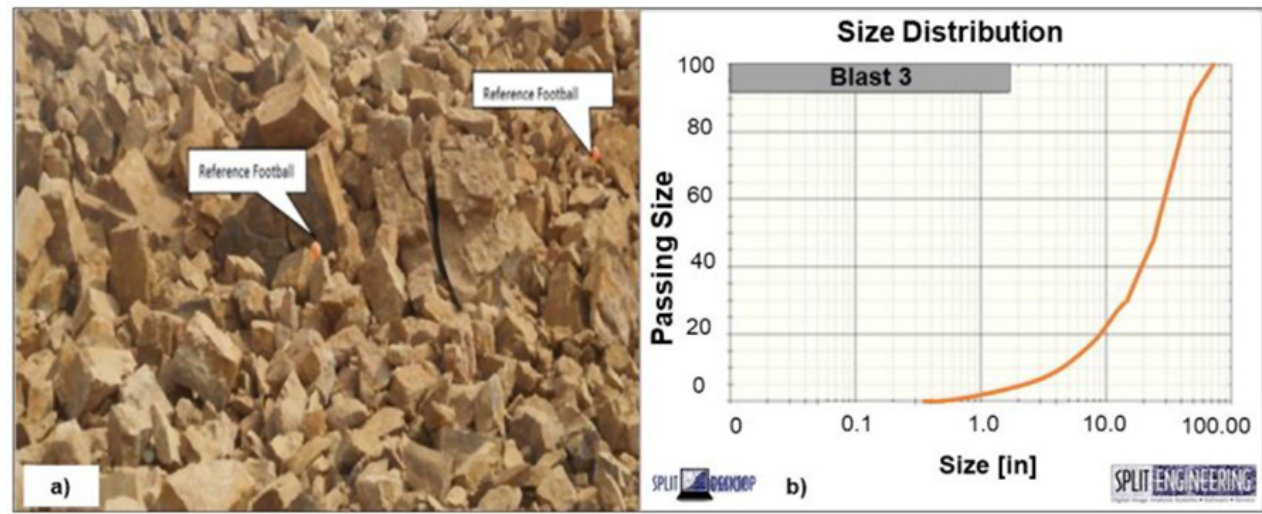

Figure 8-Blast 3. (a) Muckpile after the blast and (b) cumulative size distribution
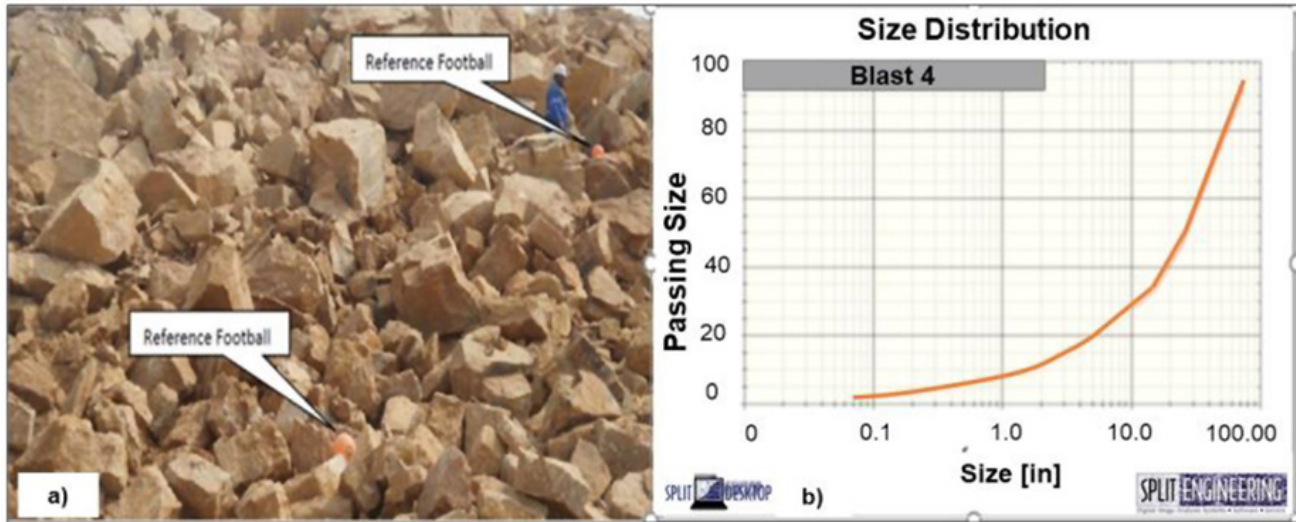

Figure 9-Blast 4. (a) Muckpile after the blast and (b) cumulative size distribution 


\section{Improving the environmental and economic aspects of blasting in surface mining}

Lastly, the blast 5 results were compared with those of blast 6. Stemming plug 3 (cement mortar/slurry) was used in blast 5 , while blast 6 employed conventional stemming. The results for blast 5 show a $D_{50}$ of 20 inches and $D_{80}$ of 50 inches. The percentage of material b of 15 inches with $D_{80}$ at 35 inches and $28 \%$ of the material less than the fines cut. There were no fragments beyond the permissible limit of the crusher, and the maximum size of the boulders was 46.21 inches. Figure 10 shows the post-blast image and screenshot from Split Desktop. For blast 6 , the $D_{50}$ and $D_{80}$ were 25 and 75 inches, with $22 \%$ of the material below the fines cut and $10.4 \%$ larger than the required size limit of the crusher. The maximum size of the boulder was 92 inches. Figure 11 shows the post-blast image and screenshot from Split Desktop.

The results for blasts 1 and 2 showed that the incorporation of stemming plugs improved gas retention, resulting in a more homogeneous particle size distribution. For a conventional blast (blast 2), the particle size distribution indicated excessive crushing and huge boulders. Although finer particle sizes are easy to haul and require less power during comminution, the accumulation of boulders is a problem as to their manoeuvrability, and secondary blasting is an economic and operational burden with higher safety risks. Comparison of both blasts suggested that blast 1 had a uniform explosives energy utilization and did not require secondary blasting. Stemming plug 1 appears therefore to be a useful product that should be incorporated in the blasting operation.
The worker feedback (Table I) suggests that the use of stemming plug 1 requires one extra minute, with minimal learning needed for its inclusion in blasting practice.

Troubleshooting of stemming plug 1 was simple, as in case of a blockage no extra handling accessory was needed at the blast location. The incorporation of stemming plug 2 required 7 extra minutes for each blast-hole and extended the loading time significantly. In case of installation failures (which occurred 30 times during the tests), the total time of application is greatly increased, thereby delaying the overall blasting operation. The workers also had to make sure they carried the required inflation set-up to the blast site and used it correctly to avoid overfilling. However, with more usage and practice, total application time is expected to reduce. Thus, stemming plug 2 was less user-friendly than stemming plugs 1 and 3 , requiring longer operational time and adding cognitive load on the blasting crew. Stemming plug 3 took five extra minutes to load each blast-hole and workers were required to master mortar mixing skills. Due to the quick setting time of cement, the mixture had to be prepared in small batches, which caused workers to dislike stemming plug 3. Of all the tested plugs, the operational efficiency of stemming plug 1 was the best.

Another type of stemming plug (the self-inflating plug) might be a good alternative to stemming plug 1 as the installation procedure is similar to that for stemming plug 1 . However selfinflating stemming plugs were not available for this work.
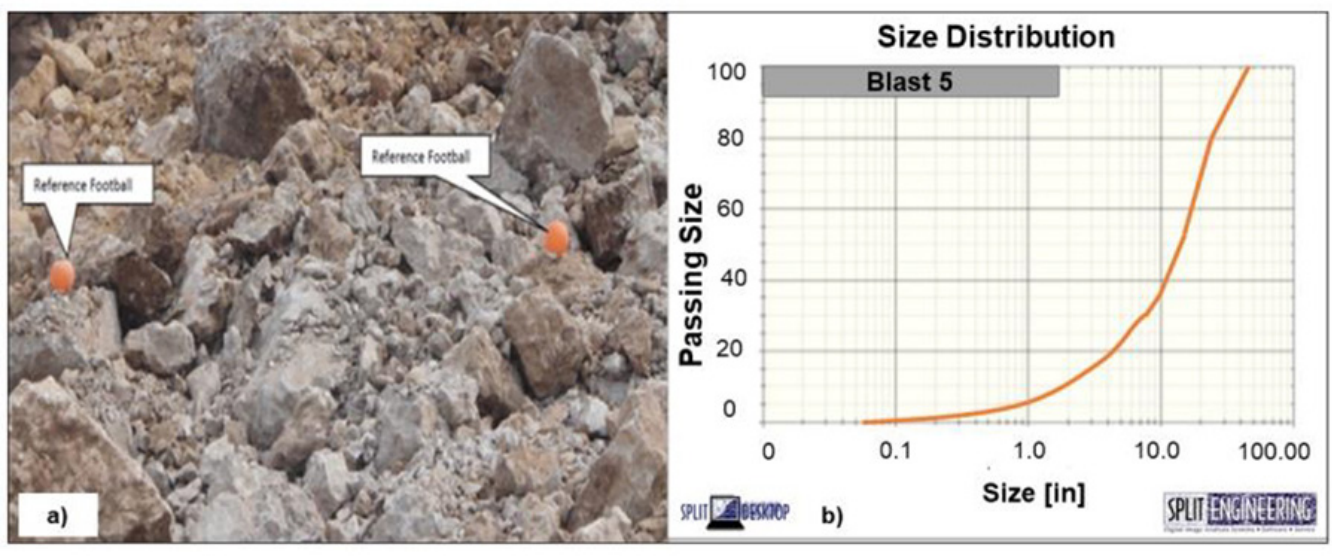

Figure 10-Blast 5. (a) Muckpile after the blast and (b) cumulative size distribution
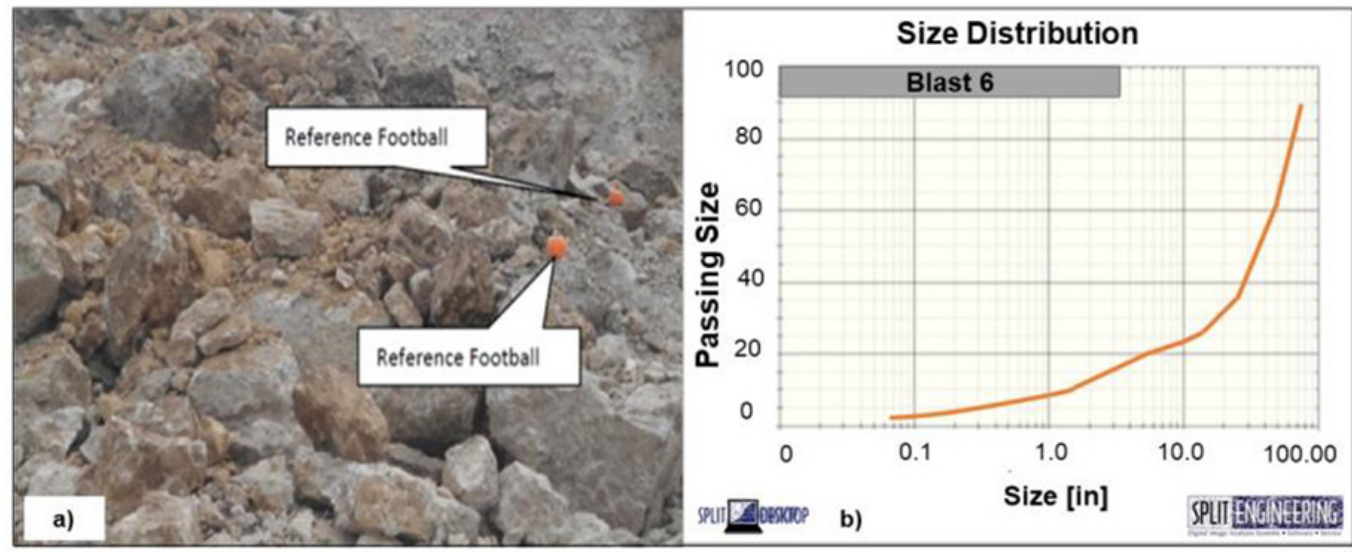

Figure 11-Blast 6. (a) Muckpile after the blast and (b) cumulative size distribution 


\section{Improving the environmental and economic aspects of blasting in surface mining}

A modification of stemming plug 3 exists in the form of ready-made cartridges that expand while being lowered down the blast-hole. No work on these types of stemming plug could be located in the literature. Such stemming plugs are available, although not in Pakistan. The authors therefore relied on the best available source for information.

The performance of all stemming plugs tested was found to be acceptable and their incorporation improved the blast fragmentation. The comparison based on rock fragmentation suggested that stemming plug 3 resulted in the best rock breakage, stemming plug 1 the second-best blast results, whereas stemming plug 2 resulted in the least promising rock fragmentation. On the other hand, based on worker feedback, stemming plug 1 was most favoured and stemming plug 3 the least preferred.

\section{Economic evaluation}

As indicated in Table II, all blasts that were performed without stemming plugs required secondary blasting.This material required additional hauling and loading. Based on the accounts of labour, explosives, and machinery cost, an economic analysis was conducted comparing blasts with stemming plugs and with conventional stemming. Table III indicates the cost of explosives and other accessories. Along with the added explosives cost for secondary blasting, hauling, and manoeuvring cost is also increased, as after the second blast all such operations need to be repeated. As per information received from the management of DG Cement, the operational cost of machinery was calculated on an hourly basis.

For boulder blasting, drilling operations must be dedicated, therefore one drilling machine must spend six drilling hours. One complete shift of the blasting team was employed for boulder blasting. Expenses incurred for lubricants, filters, and spare parts were incorporated under the maintenance head. Fuel consumption per hour is given in Table IV, along with fuel rates received from the refinery. These rates are lower than the prevalent market price due to bulk contracting and the absence of a third party.

\section{Table III}

\section{Explosives prices}

\begin{tabular}{|l|c|}
\hline Product & Price (US\$) \\
\hline Nonel & $\$ 1.75$ per unit \\
Detonating cord & $\$ 0.24$ per metre \\
Safety fuse & $\$ 0.09$ per metre \\
Plain detonator & $\$ 0.16$ per unit \\
Ammonium nitrate & $\$ 0.47$ per kg \\
Blaster & $\$ 2.48$ per kg \\
Dynamite (Wabox) & $\$ 4.14$ per kg \\
\hline
\end{tabular}

\section{Table $V$}

\section{Detailed costing of secondary blasting}

\begin{tabular}{|l|c|c|c|}
\hline Machinery & Cost & Hours (or no. of units per kg) & Total cost \\
\hline Drilling machine & $\$ 28.64$ & 6 & $\$ 171.84$ \\
Haul truck & $\$ 17.69$ & 4 & $\$ 70.76$ \\
Front shovel & $\$ 32.15$ & 4 & $\$ 128.60$ \\
Dozer & $\$ 25.30$ & 2 & $\$ 50.60$ \\
Nonel & $\$ 1.75$ per unit & 15 & $\$ 26.21$ \\
Safety fuse & $\$ 0.09$ per metre & 2 & $\$ 0.19$ \\
Plain detonator & $\$ 0.16$ per unit & 1 & $\$ 0.16$ \\
Ammonium nitrate & $\$ 0.47$ per kg & 20 & $\$ 9.40$ \\
Blaster & $\$ 2.48$ per kg & 14.28 & $\$ 35.35$ \\
Grand total (US\$) & $\$ 493.11$ & & \\
\hline
\end{tabular}

Table VI

\section{Cost of each plug}

\begin{tabular}{|l|c|c|c|}
\hline $\begin{array}{l}\text { Type of } \\
\text { plug }\end{array}$ & $\begin{array}{c}\text { Unit price } \\
\text { (US\$) }\end{array}$ & $\begin{array}{c}\text { Total no. of } \\
\text { units used }\end{array}$ & $\begin{array}{c}\text { Total cost } \\
\text { (US\$) }\end{array}$ \\
\hline Plug 1 (plastic moulded) & $\$ 2.6$ & 47 & $\$ 122.20$ \\
Plug 2 (air-plug) & $\$ 1.06$ & 80 & $\$ 84.80$ \\
Plug 3 (cement mortar) & $\$ 3.19$ & 56 & $\$ 178.64$ \\
\hline
\end{tabular}

As the blasting crew and machine operators were on monthly wages and their extra hours did not have any effect on costs, that expense is not included in the economic analysis. The rest of the extra operational time is quantified in the form of US dollars. Table $\mathrm{V}$ indicates the time utilized by each item of machinery along with the cost and amount of explosives used in secondary blasting. Blast 2 resulted in only $5.25 \%$ oversized material. Applying the normalizing method, blasts 4 and 6, will cost around an additional $\$ 754.31$ and $\$ 976.81$ respectively.

The cost of the stemming plug was an additional cost in the conventional system, but that helped in reducing the cost for secondary blasting. The costs per hour (or any other parameter) given to gauge the economics of operation are site-specific. Table VI lists the cost of each stemming plug and the number used. As all other parameters remained the same and no extra shift was needed for operators and labour when utilizing the stemming plugs, thus no extra installation cost was added. Furthermore, the shipping cost of plugs was considered. Stemming plug 1 is a rigid plastic material with no installation issues, therefore the numbers are the same as what was actually used. Stemming plug 2 suffers from bursting problems, and approximately 30 air-plugs were wasted so their cost was also added to the total number. This is an inherent issue with air-plugs. Similarly, based on the site conditions, six additional units were considered for cement mortar due to wastage during mixing, pouring, and sticking of mortar in the container.

Table IV

\section{Fuel consumption and maintenance}

\begin{tabular}{|l|c|c|c|}
\hline Machine & Fuel (I/h) & High-speed diesel (US\$/h) & Maintenance cost/hour (US\$/h) \\
\hline Drilling machine & 40 & $\$ 25.90$ & $\$ 2.74$ \\
Haul truck & 25 & $\$ 16.19$ & $\$ 1.5$ \\
Front shovel & 45 & $\$ 29.14$ & $\$ 3.01$ \\
Dozer & 35 & $\$ 22.67$ & $\$ 2.63$ \\
\hline
\end{tabular}




\section{Improving the environmental and economic aspects of blasting in surface mining}

\section{Table VII}

\section{Cost comparison: stemming plugs vs secondary blasting}

\begin{tabular}{|l|c|c|c|c|} 
Type of plug & Total cost (US\$) & Total cost of secondary blasting (no plug) (US\$) & Savings per blast (US\$) & Annual savings (280 blasts) \\
\hline Plug 1 & $\$ 122.20$ & $\$ 493.11$ & $\$ 370.91$ & $\$ 103854.80$ \\
Plug 2 & $\$ 84.80$ & $\$ 754.31$ & $\$ 669.51$ & $\$ 187462.80$ \\
Plug 3 & $\$ 178.64$ & $\$ 976.81$ & $\$ 798.17$ & $\$ 223487.60$ \\
\hline
\end{tabular}

Table VII indicates the main crux of the economic analysis. The cost comparison shows that the use of plugs brings significant annual cost savings in all three cases. The greatest saving was achieved with stemming plug 3 . However, the comparative difficulty of installation remains a challenge wirh this plug.

\section{Conclusions}

Three different blast-hole stemming systems were tested to investigate the effect on blasting efficiency (fragmentation) and economics. The fragmentation analysis was carried out based on the largest boulder size, $D_{50}, D_{80}$, cumulative size distribution, and percentage of fragmentation greater than the limit of 75 inches. Incorporation of stemming plugs in the blasting operation resulted in better rock fragmentation and production of fewer boulders. The economic benefits of using stemming plugs are considerable. Mineworkers' perceptions were also considered in the comparison of different stemming plugs. The plastic moulded plug yielded the best fragmentation, and the cement mortar plug was found to be the most economical. The performance of the air plug was reasonable as regards both blast outcome and economics. A conventional stemming system results in $5-11 \%$ oversized boulders. Stemming plugs can reduce costs by US $\$ 0.13-0.2$ million for a quarry conducting 280 annual blasts of $16000 \mathrm{t} /$ day. This amounts to savings of US\$ 0.03-0.045 per ton of limestone. Similar studies could be carried out in different geological environments to further evaluate the impact of stemming plugs on the economics of drilling and blasting at other operations. Aggregates are widely used as stemming material and their comparison with commercial stemming systems (as tested in this work) could also be considered for future work.

\section{Acknowledgements}

The authors would like to acknowledge the Vari-Stem company for providing free stemming plugs. Special thanks to Pagel Chemicals for providing chemicals/additives for the cement mortar plugs, and Mr Tanzeel Jabbar, and Ahsan Saleem for providing air-plugs. This work would not have been possible without the support of DG. Khan Cement Company, Mr Rafi Ur Rehman, Mr Hidayat Shah, Mr Reehan Shoukat, Mr Sajid Ur Rehman, and their blasting team. Special thanks to the reviewers for their useful comments on improving our work.

\section{Conflict of interest statement}

This paper might positively influence Vari-stem stemming plugs or Pagel Chemical. Stemming plug 2 do not have a trademark name or specific brand that can be influenced. Other than that, on behalf of the other author, the corresponding author states that there is no conflict of interest of which we are aware at this point.

\section{References}

BARTLEY, D. 2002. Blast fragmentation enhancement using MOCAP Vari-Stem holes plugs. http://www.varistem.com/PDF/DBAstudy1.pdf

Bhaskar, A., Baranwal, A., Ranjan, P., Jena, T., Shkhar, M., and Chakraborty, D. 2019. Application of plastic funnel in blast hole to improve blasting efficiency of opencast coal mine at West Bokaro. Proceedings of the 2019 Coal Operators' Conference, University of Wollongong, 18-20 February 2019 Aziz, N. and Kininmonth, R. (eds), https://ro.uow.edu.au/coal/752

BiLiм, N., Çецік, A., and Кекес̧, В. 2020. Assessment of the effect of blasthole design parameters on total cost in quarries. Arabian Journal of Geosciences, vol. 13, no. 21. p. 1168. https://doi.org/10.1007/s12517-020-06181-1

Brinkmann, R. 1990. Experimental study of the effects of shock and gas penetration in blasting. Proceedings of the 3rd International Symposium on Rock Fragmentation by Blasting, Brisbane, 26-31 Aug 1990. Australasian Institute of Mining and Metallurgy, Melbourne. https://doi.org/10.1016/01489062(92)93965-m

CevizcI, H. 2019. Comparison of the efficiency of plaster stemming and drill cuttings stemming by numerical simulation. Journal of the Southern African Institute of Mining and Metallurgy, vol. 119, no. 5. pp. 465-470. https://doi. org/10.17159/2411-9717/18/068/2019

Cevizcl, H. 2012. A newly developed plaster stemming method for blasting. Journal of the Southern African Institute of Mining and ssMetallurgy, vol. 112, no. 2. p.1071. http://www.scielo.org.za/scielo.php?script=sci_ arttext\&pid=S2225-62532012001200016

Cevizci, H. 2013. A new stemming application for blasting: a case study. REM: Revista Escola de Minas, vol. 66, no. 4. pp. 513-519. https://doi.org/10.1590/ S0370-44672013000400017

Cevizci, H. 2014. Fragmentation, cost and environmental effects of plaster stemming method for blasting at a basalt quarry. Archives of Mining Sciences, vol. 59, no. 3. pp.835-846. https://doi.org/10.2478/amsc-2014-0058

Cevizci, H. and Ozkahraman, H.T. 2012. The effect of blast hole stemming length to rockpile fragmentation at limestone quarries. International Journal of Rock Mechanics and Mining Sciences, vol. 53. pp. 32-35. https://doi.org/10.1016/j. ijrmms.2012.04.005

Chiapetta, R. and Wyciskalla, J. 2004. Bottom-hole and multiple power decks Independent test results of a new blasting technique. Quarry Management, vol. 31. pp. 21-32.

Choudhary, B.S. and Rai, P. 2013a. Stemming plug and its effect on fragmentation and muckpile shape parameters. International Journal of Mining and Mineral Engineering, vol. 4, no. 4. p. 296. https://doi.org/10.1504/IJMME.2013.056854

Choudhary, B.S. and RAI, P. 2013b. Stemming plug and its effect on fragmentation and muckpile shape parameters. International Journal of Mining and Mineral Engineering, vol. 4, no. 4. pp. 296-311. https://doi.org/10.1504/ IJMME.2013.056854

EloRANTA, J. 1994. Stemming selection for large-diameter blastholes. https:// elorantaassoc.com/download/Papers/E\&A_Stemming_Selection_for_Large_ Diameter_Blastholes.pdf 


\section{Improving the environmental and economic aspects of blasting in surface mining}

Gomes-Sebastiao, G.L. and De Graaf, W.W. 2017. An investigation into the fragmentation of blasted rock at Gomes Sand. Journal of the Southern African Institute of Mining and Metallurgy, vol. 117, no. 4. pp. 321-328. https://doi. org/10.17159/2411-9717/2017/v117n4a2

Ipmawati, M.R., Nainggolan, D.R., Wiyono, B., and Sunarya, R. 2018. Effect doubleprimer placement for improving the fragmentation on harder material in stemming column: A case study. IOP Conference Series: Earth and Environmental Science, vol. 212, no. 1. 12064. https://doi.org/10.1088/1755$1315 / 212 / 1 / 012064$

Jenkins, S. and Floyd, J. 2000. Stemming enhancement tests. Proceedings of the Annual Conference on Explosives and Blasting Technique. International Society of Explosives Engineers. pp. 191-204.

KABWE, E. 2018. Velocity of detonation measurement and fragmentation analysis to evaluate blasting efficacy. Journal of Rock Mechanics and Geotechnical Engineering, vol. 10, no. 3. pp. 523-533. https://doi.org/10.1016/j. jrmge.2017.12.003

KABWE, E. and BANDA, W. 2018. Stemming zone fragmentation analysis of optimized blasting with top-column air decks. CIM Journal, vol. 9, no.1. https://doi. org/10.15834/cimj.2018.1

Khandelwal, M. and Singh, T.N. 2006. Prediction of blast induced ground vibrations and frequency in opencast mine: A neural network approach. Journal of Sound and Vibration, vol. 289, no. 4-5. pp. 711-725. https://doi.org/10.1016/j. jsv.2005.02.044

Kojovic, T. 2005. Influence of aggregate stemming in blasting on the SAG mill performance. Minerals Engineering, vol. 18, no. 15. pp. 1398-1404. https://doi. org/10.1016/j.mineng.2005.02.012

Kopp, J.W. 1987. Stemming ejection and burden movements of small borehole blasts. Information Circular, US Bureau of Mines. 15. pp. https://www.osti.gov/ biblio/6055364

Marinho, L.F.G., Vasconcelos, H.G., Lusk, B., and Rapucci, G.AP. 2017. Achieving effective confinement through utilization of non-newtonian fluid mixture as stemming structure. Revista Escola de Minas, vol. 70, no. 1. pp. 77-83. https:// doi.org/10.1590/0370-44672016700077

Mohamad, E.T., Armaghani, D.J., Hajihassani, M., Faizi, K., and Marto, A. 2013. A simulation approach to predict blasting-induced flyrock and size of thrown rocks. Electronic Journal of Geotechnical Engineering, vol. 18B. pp. 365-374. http://www.ejge.com/2013/Ppr2013.031alr.pdf

Mohamad, E.T., Armaghani, D.J., Nooranı, S.A., SaAd, R., and Abad, S.V.A.N.K. 2012. Prediction of flyrock in boulder blasting by using artificial neural network. Electronic Journal of Geotechnical Engineering, vol. 17R. pp. 2585-2595. http://www.ejge.com/2012/Ppr12.219alr.pdf

Neves, P.F., e Silva, M.C., Paneiro, G., Bernardo, P., and Cardoso, J.G. 2016. Blasting performance when using articulated air-deck stemming systems with plug. Proceedings of the 16th International Multidisciplinary Scientific GeoConference SGEM2016, Science and Technologies in Geology, Exploration and Mining, book 1, vol. 2. pp. 119-126. https://doi.org/10.5593/sgem2016/b12/s03.016

$\mathrm{R}_{\mathrm{AI}}, \mathrm{P}$. and IMPERIAL, F. 2005. Mesh area vis-à-vis blast performance in a limestone quarry of the Philippines. Fragblast, vol. 9, no. pp. 219-232. https://doi. org/10.1080/13855140600761798

RaI, P., Ranjan, A.K., and Choudhary, B.S. 2008. Achieving effective fragmentation - A case study on the role of the stemming column on fragmentation. Quarry Management, vol. 35, no. 2. p. 17.

Ramulu, M. 2012. Special Tunnel Blasting Techniques for Railway Projects. Intechopen.

Saharan, M.R., Sazid, M., and Singh, T.N. 2017. explosive energy utilization enhancement with air-decking and stemming plug, "SPARSH". Procedia Engineering, vol. 191. pp. 1211-1217. https://doi.org/10.1016/j. proeng.2017.05.297

Sazid, M., Saharan, M.R., and Singh, T.N. 2016. Enhancement of the explosive energy utilization with the application of new stemming contrivance. International Journal of Innovative Science and Modern Engineering, vol. 4, no. 2. https:// www.ijisme.org/wp-content/uploads/papers/v4i2/B0955014215.pdf

Sazid, M., Saharan, M., and Singh, T. 2012. Effective explosive energy utilization for engineering blasting - initial results of an inventive stemming plug, SPARSH. Harmonising Rock Engineering and the Environment. CRC Press. pp. 1265-1268. https://doi.org/10.1201/b11646-237

SHARma, S.K. AND RAI, P. 2015. Investigation of crushed aggregate as stemming material in bench blasting: A case study. Geotechnical and Geological Engineering, vol. 33, no. 6. pp. 1449-1463. https://doi.org/10.1007/s10706015-9911-7

Singh, D.P. and SASTRY, V.R. 1988. Effect of controllable blast design factors on rock fragmentation. Journal of Mines, Metals and Fuels, vol. 36, no. 12. pp. 539-548. https://www.osti.gov/etdeweb/biblio/6309688

SiNGH, T.N. and SinGH, V. 2005. An intelligent approach to prediction and control ground vibration in mines. Geotechnical and Geological Engineering, vol. 23, no. 3. pp. 249-262. https://doi.org/10.1007/s10706-004-7068-X

Stavrakas, V., Papadelis, S., and Flamos, A. 2019. An agent-based model to simulate technology adoption quantifying behavioural uncertainty of consumers. Applied Energy, vol. 255. 113795. https://doi.org/10.1016/j.apenergy.2019.113795

Trivedi, R., Singh, T.N., and Raina, A.K. 2014. Prediction of blast-induced flyrock in Indian limestone mines using neural networks. Journal of Rock Mechanics and Geotechnical Engineering, vol. 6, no. 5. pp. 447-454. https://doi.org/10.1016/j. jrmge.2014.07.003

UR Rehman, A. 2017. Design and development of stemming plug to enhance blast performance. MSc thesis, University of Engineering and Technology, Lahore. https://doi.org/10.13140/RG.2.2.15991.47523

UR ReHman, A., Emad, M.Z., and Khan, M.U. 2020. Role of ergonomics in the selection of stemming plugs for surface mining operations. Archives of Mining Sciences, vol. 65, no 1. pp. 59-70. https://doi.org/10.24425/ams.2020.132706

YAng, D., Zhao, Y., Ning, Z., Lv, Z., and Luo, H. 2018. Application and development of an environmentally friendly blast hole plug for underground coal mines. Shock and Vibration in Deep Mining Science. https://doi.org/10.1155/2018/6964386

YANG, L. H. and Liu, S.Q. 2010. Temperature-control blasting underground coal gasification in the inclined coal seams with a short wall. Energy Sources, Part A: Recovery, Utilization and Environmental Effects, vol. 32, no. 6. pp. 532-541. https://doi.org/10.1080/15567030802612242

YANG, L.H., PANG, X.L., Liu, S.Q., and Chen, F. 2010. Temperature and gas pressure features in the temperature-control blasting underground coal gasification. Energy Sources, Part A: Recovery, Utilization and Environmental Effects, vol. 32, no. 18. pp. 1737-1746. https://doi.org/10.1080/15567030903078087

ZHANG, Z.X., Hou, D.F., Guo, Z., and HE, Z. 2020. Laboratory experiment of stemming impact on rock fragmentation by a high explosive. Tunnelling and Underground Space Technology, vol. 97. https://doi.org/10.1016/j.tust.2019.103257

ZHu, Z., XIE, H., and Moнаnту, B. 2008. Numerical investigation of blasting-induced damage in cylindrical rocks. International Journal of Rock Mechanics and Mining Sciences, vol. 45, no. 2. pp. 111-121. https://doi.org/10.1016/j. ijrmms.2007.04.012 